\title{
Docência no ensino superior: dilemas contemporâneos
}

\begin{abstract}
RESUMO: Este artigo discute a docência no ensino superior, destacando os aspectos relacionados à identidade profissional e aos dilemas enfrentados por uma Universidade Pública do Estado do Rio Grande do Norte, quando analisados sob a perspectiva das exigências da política educacional para esse nível de ensino. A identidade docente é, acima de tudo, uma construção epistemológica e profissional, na qual saberes diversos se articulam entre si. Procura-se, por fim, realçar que a docência não se constitui objeto de atuação desprofissionalizada, exigindo, portanto, das universidades a utilização de estratégias de formação no próprio espaço de trabalho.

PALAVRAS-CHAVE: Docência. Ensino superior. Identidade profissional.
\end{abstract}

Para marcar o início dessa discussão, indaga-se: como, ao longo da história da educação brasileira, foi se configurando o ser professor no ensino superior? De ser vocacionado, com dom inato, nasce o exercício da docência. Hoje, a perspectiva de ser professor extrapola esse tipo de concepção para se fundamentar em perspectivas de ordem mais política, social e epistemológica. Portanto, de vocacionado ao processo de profissionalização do professor está o percurso de construção histórica e social da docência. Desta feita, as exigências de outrora para ser professor não eram as mesmas da contemporaneidade e não teriam como sê-las, pois, diante dos avanços técnicos e científicos, não há espaço para a estagnação do conhecimento. Avança-se o conhecimento e com ele rompe-se a perspectiva da docência como pura vocação, como dom inato, exigindo de nós um mergulho mais profundo na dimensão teórica e prática da docência como uma profissão.

Inicialmente, assumo a premissa de que a docência no ensino superior - em si - já é um dilema, tendo que as instituições se organizarem e elegerem mecanismos para seu enfrentamento. Assumo também que a temática para este momento é igualmente ampla, mas suficientemente necessária e importante de ser fomentada no interior da Universidade do Estado do Rio Grande do Norte (UERN) ${ }^{1}$. Ela, por ser bastante provocativa e convidativa, suscita duas questões de fundo, que estabelecem entre si conexões e complementações: a) a construção do exercício profissional docente no ensino superior; b) a inserção desse profissional no contexto da contemporaneidade, focalizando os dilemas, os desafios que os docentes do ensino superior enfrentam na atual configura-
Arilene Maria Soares Medeiros

Professora do Departamento de Educação da UERN

arilene.medeiros@bol.com.br
(1) A escolha em discutir a docência superior no âmbito da UERN advém principalmente de meu pertencimento institucional. Além disso, considera-se a ausência de disso, considera-se a ausência de uma análise mais pontual acerca da docência, das dificuldades que os profissionais enfrentam no cotidiano de suas práticas em instituições que buscam se afirmar como

Universidade. No fundo, o intuito 
em desenvolver tal análise é contribuir, de alguma maneira, com o debate que nos soa tão crucial neste momento histórico de desafios gigantescos, tanto do ponto de vista político, quanto acadêmico. ção da realidade social, política, econômica e cultural. A docência no ensino superior tem suas razões epistemológicas e operacionais sobre as quais teremos que apurar e propor encaminhamentos diversos, para não engessar o processo educativo mediado pelas funções do ensino, da pesquisa e da extensão.

As discussões acerca do professor - sua formação e seu exercício profissional - têm recebido, nas últimas décadas, bastante atenção de pesquisadores nacionais e internacionais. Digo em outros escritos que o campo de investigação centrado e verticalizado nas questões e problemáticas relativas ao professor passa por um verdadeiro estado de ebulição (MEDEIROS, 2005). A constatação desse estado se evidencia no número de teses e de dissertações defendidas em todo o Brasil, dos inúmeros encontros, simpósios, que elegem o professor como razão central dos eventos nacionais e internacionais. A título de ilustração, faço referência ao XIII Encontro Nacional de Didática e Prática de Ensino(ENDIPE), por ser um encontro expressivo no contexto das discussões em torno do professor, de sua prática e de seus desafios atuais. Nesse encontro, que aconteceu na Universidade Federal do Pernambuco, em abril de 2006, foram apresentados 42 simpósios (mesas-redondas encomendadas pelo próprio evento); 223 painéis (constituídos, geralmente, por três pesquisadores em torno de uma temática comum); 623 pôsteres e 49 mini-cursos. Os quantitativos são reveladores no sentido de demonstrar o crescimento desse campo de investigação que se (pre)ocupa com o professor.

Este trabalho se organiza em torno de dois aspectos: 1) a questão da identidade profissional do docente de ensino superior, explicitando aspectos relativos à sua profissionalização; 2) os desafios, dilemas e perspectivas referentes ao trabalho docente no ensino superior, com detalhamento para a realidade da UERN, mas que, decerto, outras universidades brasileiras vêm enfrentando os mesmos ou outros desafios, quando colocados frente às exigências das políticas educacionais para esse nível de ensino.

\section{Identidade Profissional do Docente de Nível Superior: breves apontamentos}

Em geral, os docentes do ensino superior são aqueles profissionais que não fizeram a opção profissional primeira de ser 
professor(a). São profissionais das diferentes áreas do conhecimento, mas que, por alguma razão, acabam chegando a ser professor do ensino superior. Muitos docentes do ensino superior, ao serem questionados pela profissão que exercem, identificam-se primeiramente como sendo o médico, o dentista, o advogado, o contador, o físico, o engenheiro, o jornalista, o radialista, seguido, às vezes, pela identificação de professor universitário, porque responder apenas professor pode dar margem a uma identidade socialmente inferior. Inegavelmente, ao longo dos anos, o professor vem perdendo seu status em virtude de uma deflagrada desvalorização profissional, contribuindo, sobretudo, para o aprofundamento da proletarização docente.

A função docente apresenta-se como função de baixo prestígio social e passa por mudanças significativas. Nesse quadro, alguns teóricos afirmam que vivenciamos uma situação de mal-estar docente resultante dos efeitos das condições psicológicas e sociais, nas quais a docência é assumida englobando questões como formação, prática, identidade e carreira profissional, dentre outras. (DOURADO, 2001, p. 51)

O baixo prestígio social do professor, principalmente do professor da educação básica, consiste num aspecto fundamental para se compreender como a docência foi se configurando como uma profissão de menor prestígio se comparada às profissões mais antigas, como a do engenheiro, do médico, do advogado, do dentista, traduzindo a do professor como uma semiprofissão. Guimarães (2006, p.135) considera a denominação semiprofissão inadequada para referir-se à profissão docente, na medida em que se "[...] atribui à docência um estatuto de meio profissional, de algo que não se completa", reforçando, sobretudo, o rebaixamento e empobrecimento da docência como uma profissão. De fato, a idéia do meio profissional - em virtude da coisa que não se completa - também me soa inadequado, por indexar uma concepção de profissional que não é por inteiro, mas pela metade. Somos todos inteiros, entretanto, temos nossos defeitos, nossos limites, nossas crises, nossos sonhos e desencantamentos. Não é pelo fato de apresentarmos limites que somos pela metade. Acredito que o mesmo raciocínio se aplica (ou deveriam se aplicar) à docência como profissão, pois a compreensão de uma profissão que se faz pela metade desconsidera, segundo meu entender, as 
lutas desencadeadas em prol da concepção de um profissional que está em processo de profissionalização.

Assim, ser professor é pertencer a um oficio cujo estatuto profissional está num processo histórico de constituição. Ser professor é ser um profissional. Contudo, é necessário levar em consideração traços específicos dessa profissão e os pressupostos que a fundamentam a aspiração de profissional. (GUIMARÃES, 2006, p.135)

Quando a discussão se refere à identidade profissional docente, os questionamentos mais comuns são: o que é ser docente? Em que consistem as diferenças entre a docência e as outras profissões? Que saberes se fazem imprescindíveis aos docentes? Quais as bases que fundamentam seu estatuto profissional? Qual o lócus da formação do docente de nível superior? Percebe-se que são inúmeros os questionamentos em torno do docente e de sua identidade profissional. Também não são poucas as iniciativas de respostas.

Endossando a idéia de Guimarães, considero que a docência consiste numa profissão, cabendo-nos pensá-la nos contornos mais gerais de sua profissionalização. Assegurar a docência como profissão significa dizer que ela não é simplesmente ocupação, uma vocação ou que ela se traduz em mera semiprofissão. É uma profissão que ocupa particularidades e especificidades no tecido social, porque o próprio fenômeno educativo tem uma natureza diferenciada dos demais fenômenos sociais e naturais. Costuma-se pensar que o produto da educação seja o ensino, porque o que se paga ao docente é aula. Paro (1997) acredita que o produto da educação não é a aula, mas a transformação ocorrida na personalidade viva dos indivíduos mediante o ensino. A aula, o ensino não é o produto, mas o processo. Daí, percebe-se que as discussões sobre o ensino, o professor, a educação são suficientemente complexas para impressão de visões aligeiradas, inclusive perpassando por algumas que chegam a reduzir o ensino a uma ação social qualquer, delegando aos profissionais das mais variadas áreas do conhecimento saberes e poderes para condução da docência no ensino superior, sem nunca terem tido uma formação pedagógica básica.

O conceito de profissão é uma construção que se manifesta em oposição ao amadorismo que muitos defendem, quando a matéria em questão é a docência. Uma diferença básica entre o

74 R. Faced, Salvador, n.12, p.71-87, jul/dez. 2007 
profissional e o amador precisa ser colocada, a fim de que nossa discussão possa avançar na perspectiva da profissionalização docente. Profissional é quem coloca em prática um determinado trabalho, tendo 'pleno' conhecimento e consciência do que faz; amador não conhece, por dentro, o trabalho que realiza, faz não porque realmente sabe ou tem consciência do que faz, mas faz porque gosta, interessa-se e quer. Essa diferença fundante entre o profissional e o amador é mais explicitamente demarcada em outras profissões e menos no âmbito da decência. Ninguém pode ser médico sem que se tenha uma formação inicial. Porém, pode ser docente (professor) sem formação inicial mínima.

A formação inicial deve dotar de uma bagagem sólida nos âmbitos científico, cultural, contextual, psicopedagógica e pessoal que deve capacitar o futuro professor ou professora a assumir a tarefa educativa em toda sua complexidade, atuando reflexivamente com a flexibilidade e o rigor necessários, isto é, apoiando suas ações em uma fundamentação válida para evitar cair no paradoxo de ensinar a não ensinar. (IMBERNÓN, 2002, p.66)

A história da educação brasileira nos mostra que, ao longo de muitos anos, para o exercício docente não se exigia formação inicial para tal, bastava que o interessado detivesse um pouco mais de conhecimento do que os alunos para se transformar num professor. Além do mais, muitos professores chegaram a ser docentes sem formação, tendo como pré-requisito a indicação política. Hoje, quando a LDB 9.394/96, em seu Art. 67, determina que o ingresso ao magistério somente por concurso público de provas e títulos, reforça a necessidade de profissionalizar o ingresso do professor ao magistério. Nas outras profissões, mesmo com a prerrogativa da indicação política, preservava-se a formação, o que, de certo modo, a ausência da formação no âmbito da docência consistia numa aposta ao amadorismo do professor, representando o aviltamento do processo de profissionalização docente.

A compreensão da docência como profissão e, conseqüentemente, do professor como um profissional exige-se uma análise à luz do movimento da profissionalização docente. Dentro de um quadro mais amplo, a profissionalização docente significa a constituição e a formatação de um estatuto profissional do professor que não se restringe às regras da organização e do funcionamento do trabalho em uma coletividade. 
Estatuto profissional do professor, como entendido aqui, refere-se principalmente: ao estabelecimento de contornos para a formação (inicial e continuada); à constituição de condições de trabalho (além das condições materiais, também de apoio pedagógico, relações democráticas); à garantia de remuneração condizente; à jornada de trabalho (que leve em consideração o desgaste físico e psicológico inerente a essa profissão) e, por último, ao vínculo desses trabalhadores com instituições sindicais e associativas. (GUIMARÃES, 2006, p.132)

Diante do exposto, admitir o professor como um profissional requer o estreitamento dos laços com a formação inicial e continuada, uma vez que ser profissional subentende-se a necessidade de uma formação capaz de introduzi-lo no exercício profissional, de modo menos amadorístico possível. Amadorismo na docência não se confunde com a docência como profissão. Não há condições de se defender um professor profissional sem que se supere a concepção advogada pelo senso comum de que para ser professor(a) basta que se tenha como dispositivo o domínio dos conteúdos disciplinares. Ser professor exige conhecimentos outros que não se limitam aos conteúdos disciplinas, embora este sejam igualmente indispensáveis.

A construção da identidade docente é, acima de tudo, uma construção epistemológica e profissional, na qual saberes se entrecruzam. A docência - enquanto campo de conhecimentos específicos - demanda um conjunto de quatro saberes que vale a pena conferir.

1) conteúdos das diversas áreas do saber e do ensino, ou seja, das ciências humanas e naturais, da cultura e das artes;

2) conteúdos didático-pedagógicos, diretamente relacionados ao campo da prática profissional;

3) conteúdos relacionados a saberes pedagógicos mais amplos do campo teórico da prática educacional;

4) conteúdos ligados à explicitação de sentido da existência humana individual, com sensibilidade pessoal e social. (PIMENTA; ANASTASIOU, 2005, p.166)

A compreensão da identidade docente a partir desse conjunto de saberes se complexifica no ensino superior na medida em que a maioria dos profissionais que se tornaram professores não passou por esse rastro de conhecimentos, os quais são indispensáveis à identidade profissional. Então, assim se indaga: onde e

76 R. Faced, Salvador, n.12, p.71-87, jul/dez. 2007 
de que maneira os professores do ensino superior irão discutir, apropriar-se dos conteúdos que lhes são indispensáveis? Que políticas as instituições de ensino superior, particularmente a UERN vêm adotando no sentido de acompanhar o recém-ingresso na construção de sua profissionalização docente?

Do profissional professor ao professor profissional está a desafiante construção da identidade docente no ensino superior. Uma construção não sem conflitos, sem embates, mas necessária. Com esse trajeto que tem como ponto de partida o profissional que se torna professor e como ponto de chegada o professor profissional, busca-se fomentar iniciativas acadêmicas e conceptuais capazes de superar as perspectivas do professor "prático-artesão" - aquele que julga que a prática lhe ensina -; do professor "tecnicista" - aquele que defende a compreensão de que ensinar é apenas um campo de aplicação dos conhecimentos, porque o saber didático-pedagógico se transformou em técnicas, estratégias e recursos para empreender situações de ensino -, para tornar-se um professor que reconhece o ensino como uma atividade social ampla e complexa, perpassada de saberes e, por isso, tem plena consciência de seu papel no interior da universidade e da sociedade.

Muitos professores do ensino superior acabam desvalorizando os saberes inerentes à identidade profissional docente, porque entendem e defendem ser o conhecimento da área específica o carro-chefe do ensino, dado que a literatura especializada já demonstrou insuficiente. Os professores que desconsideram a especificidade do ensino acabam se comprometendo com o amadorismo no âmbito da docência, bem como acabam contribuindo com desqualificação do trabalho docente no interior das universidades.

A docência no ensino superior é recheada de particularidades, as quais devem ser consideradas e debatidas amplamente. Pois, ser docente em uma universidade é uma atividade profissional diferente de ser professor numa escola de séries iniciais, por exemplo, onde, geralmente, o professor foi preparado para isso. No ensino superior, a função educativa basilar é a formação de profissionais, dotando-os de uma sólida formação acadêmica, cultural e científica, com o objetivo de contribuir com o desenvolvimento da sociedade brasileira. A depender da instituição em que exerça sua profissão, o docente do ensino superior precisará 
interagir com o ensino, a pesquisa e a extensão. E fazer tal interação não se constitui em tarefa simples. Ou seja, a construção da profissionalização docente no ensino superior, principalmente no âmbito das universidades, vincula-se à idéia da indissociabilidade entre o ensino, a pesquisa e a extensão, pressupondo uma forte inserção do docente em atividades que se expandem para além do ensino de graduação.

Cunha (2006) associa a profissionalização dos universitários à manutenção e ao aumento da produtividade, tornando-a presa fácil do neotecnicismo. Essas questões precisam vir ao debate para não esquecermos, de modo algum, que a profissionalização docente no âmbito da universidade no mundo contemporâneo traz em si outros determinantes para os quais "[...] nem o estereótipo da profissão científica nem o da prática interpretativa, em separado, conseguem dar conta do recado" .(CUNHA, 2006, p.7)

Uma outra questão relativa à identidade profissional docente do ensino superior diz respeito ao lócus de sua formação. A Lei de Diretrizes e Bases da Educação Nacional (LDB) 9.394/96, no seu Art. 65, explicita que "A preparação para o exercício do magistério superior far-se-á em nível de pós-graduação, prioritariamente em programas de mestrado e de doutorado". Mas enquanto o mestrado e/ou o doutorado desses profissionais não chegam o que as Instituições de Ensino Superior (IES) estão fazendo pela formação de seus professores ou o que os professores fazem em prol de sua própria formação?

Neste sentido o intento necessário parece ser o de explicitar o lugar da formação para a docência do professor universitário e as políticas e/ou as energias que vem institucionalizando essas práticas. Elas envolvem a

formação no território do trabalho, incluindo as iniciativas institucionais de formação continuada e as que acontecem por iniciativa dos próprios grupos de professores/projetos/associações profissionais etc e a formação nos espaços/cursos que qualificam os sujeitos a disputar/manter a condição de docente da educação superior, envolvendo os Cursos de Especialização em Docência Universitária; os Cursos stricto-sensu que optam por incluir nos seus currículos a disciplina de Metodologia do Ensino Superior; experiências do Estágio de Docência, instituído pela CAPES; Programas de Pós-Graduação em Educação que abrigam candidatos de outras áreas para desenvolver pesquisas relacionadas com a pedagogia universitária; Programas de Pós-Graduação de

78 R. Faced, Salvador, n.12, p.71-87, jul/dez. 2007 
outras Áreas que possuem Linhas de Pesquisa relacionadas com a docência e/ou o ensino-aprendizagem. (CUNHA, 2006, p.12-13, grifos do autor)

Percebe-se, assim, que a formação do professor universitário não se restringe aos cursos de pós-graduação stricto sensu, mas que há uma diversidade de iniciativas institucionais que podem favorecê-la. Para tanto, espera-se que as IES estejam se mobilizando no sentido de assegurar a formação do professor no território de trabalho. Acredita-se que nenhuma iniciativa de formação do professor que atua no ensino superior possa ser dispensada, principalmente quando se percebe que este profissional acaba desenvolvendo uma prática pouco fundamentada teórica e metodologicamente. Vale muito insistir na formação deste profissional, para que se possa assegurar aos universitários uma formação também de qualidade. A formação de futuros profissionais é, não totalmente, mas em grande parte, reflexo da formação e prática de seus mestres.

\section{Docência no Ensino Superior: desafios, dilemas e perspectivas - de olho na UERN}

Torna-se indispensável, antes de tudo, fazer uma contextualização da UERN a fim de que se possa explicitar de onde se fala, de que realidade está se referindo. A UERN é uma instituição que nasce privada, na cidade de Mossoró-RN, Região Oeste do estado do Rio Grande do Norte, pela Lei Municipal no 20/68, de 28 de setembro de 1968, sendo denominada Fundação Universidade Regional do Rio Grande do Norte (FURRN). Em 08 de janeiro de 1987, há 21 anos, portanto, torna-se pública estadual pela Lei $n^{\circ}$ 5.546, passando a denominar-se Universidade Estadual do Rio Grande do Norte (URRN). O processo de estadualização é decorrência de uma intensa luta de professores e alunos em prol de sua qualidade, haja vista a constante precarização do trabalho docente. A estadualização da UERN se transforma num motivo social e político de tamanha grandeza para região, pois com ela surge não apenas a possibilidade de avançar na qualidade de seus serviços, como também o direito à educação pública superior para milhares de nordestinos(as). Do final dos anos de 1980 para cá, a UERN, Universidade do Estado do Rio Grande do Norte, como 
(2) O Campus Central fica em Mossoró e concentra o maior número de cursos: Administracão, Ciências Contábeis, Economia, Direito. Ciências Sociais, Comunicação Social, História, Geografia, Filosofia, Pedagogia, Letras, Serviço Social, Medicina, Enfermagem, Éducação Física, Música, Física, Química, Matemática, Ciência da cinco, Ciências Biológicas. Os ocalizados Assu, Caicó Natal. Patu e Pau dos Ferros. Os 11 Núcleos Avançados de Educação Superior. que funcionam em parceria com as Prefeituras, são sediados pelos municípios de Alexandria, Apodi, Areia Branca, Caraúbas, João Câmara, Macau, Nova Cruz, Santa Diante dessa estrutura a UER passa a ofertar o ensino superior em do Norte, interiorizando $=0$ ensino superior.

(3) Duas dessas propostas refletem uma parceria entre UERN e a Universidade Federal Rural do Semi-Árido (UFERSA), que juntas estão propiciando a abertura dos Cursos de Mestrado em Ciência da Computação e em Física. Outra é o Mestrado em Lingüística proposta pela UERN, Campus Avancado de Pau dos Ferros. hoje é denominada, vem demonstrando seu crescimento tanto no sentido do acesso ao ensino superior público atendendo a demandas de três estados do nordeste brasileiro: Rio Grande do Norte, Ceará e Paraíba -, como também no sentido de sua consolidação como Universidade.

Quanto ao acesso, nos últimos anos, a UERN demonstra um visível e acentuado crescimento em virtude da ampliação de sua estrutura que, atualmente, dispõe de um Campus Central, cinco Campi Avançados e 11 Núcleos² $^{2}$ Tal estrutura comporta anualmente um conjunto de 2.220 vagas.

Na realidade, a consolidação da UERN como uma Universidade não é uma tarefa social pequena, considerando as exigências da LDB 9.394/96, e da própria Reforma Universitária ensejada pelo Governo Lula que, apesar de estar direcionada às Instituições Federais de Ensino Superior (IFES), deverá provocar repercussões no contexto das demais Instituições de Ensino Superior (IES). A condição sine qua non para a UERN manter-se Universidade diz respeito à promoção da indissociabilidade entre ensino, pesquisa e extensão e, ao mesmo tempo, à disposição de, pelo menos, três cursos de pós-graduação stricto sensu. O ano de 2007 parece ser decisivo nesta perspectiva, pois três propostas são encaminhadas para avaliação da Coordenação de Aperfeiçoamento de Pessoal de Nível Superior (Capes) ${ }^{3}$, tendo sido as três aprovadas e recomendadas.

A própria LDB 9.394/96 compreende que o ensino superior possa acontecer em Universidades, em Centros Universitários, em Faculdades Integradas e Institutos ou Escolas Superiores. Interessa aqui discutir a docência no ensino superior em universidades - instituições que se caracterizam pela autonomia administrativa, financeira e pedagógica; pela indissociabilidade entre ensino, pesquisa e extensão, exigindo, portanto, um alto número de professores qualificados em nível de mestrado e de doutorado. É dessa prerrogativa que teço algumas considerações sobre os desafios, os dilemas e as perspectivas que perpassam a profissionalização do docente universitário que, diga-se de passagem, está se pontuando a realidade da docência na UERN, cuja complexidade que tece a profissionalização docente encontra-se associada ao seu próprio movimento de manutenção de status de Universidade. Quiçá, seja essa a particularidade que faz da UERN uma instituição com duplo desafio a enfrentar: a necessidade de 
sua consolidação como Universidade e da profissionalização de seus docentes. São desafios simultâneos que se interpõem à comunidade ueriana.

A docência no ensino superior se constitui numa temática polêmica. Ela - seja na educação básica ou superior - consiste numa tarefa socialmente árdua, provocadora de um desgaste físico e psicológico contínuo de quem a exerce. $\mathrm{Na}$ educação superior, a docência tem um quê a mais de complexidade, a começar pelos profissionais que a exercem sem ser, de fato, professores, que submetem, de modo geral, os saberes teóricos e práticos da educação e da docência aos específicos de seus campos profissionais. Tudo isso associado aos diferentes espaços em que este nível de ensino acontece.

Se no item anterior tive a preocupação de apresentar a construção da profissionalização docente mediante sua formação e dos saberes que costuram a sua atividade profissional. No momento, a proposição é discutir e evidenciar as condições concretas de trabalho como a outra face da moeda da profissionalização docente, pois esta pressupõe um aprofundamento também em torno das condições de trabalho, da jornada de trabalho, do plano de cargos e carreiras, do vínculo do docente com as entidades sindicais e associativas. Infere-se daqui que a profissionalização docente mobiliza múltiplas variantes, para as quais a presença e a responsabilidade dos governos são indispensáveis. Em que pese a necessidade de investir na profissionalização dos professores que atuam no ensino superior, nota-se, "[...] porém, uma certa desresponsabilização das instituições e das políticas públicas com um movimento de profissionalização da docência da educação superior". (CUNHA, 2006, p.11)

As condições de trabalho no ensino superior são bastante variadas, dependendo de como os sistemas de ensino (federal, estadual ou municipal) ou as instituições privadas decidem sua organização e funcionamento. Quanto à UERN, mesmo respeitando a jornada de trabalho, as condições estão precarizadas, porque falta a infra-estrutura básica física e pedagógica para o ensino-aprendizagem acontecer satisfatoriamente. Os cursos estão funcionando sem laboratórios, sem livros nas prateleiras. O problema é que a UERN se submeteu a uma política expansionista, sem que o poder público estadual e a administração superior da instituição tivessem ponderado as conseqüências dessa ação, in- 
clusive, a qual vem comprometendo a qualidade do ensino na educação superior.

O que tem ficado explicitamente demarcado no espaço da docência no ensino superior, particularmente na UERN, é a prevalência do ensino de graduação em detrimento da pesquisa e da extensão. O que em muitas universidades brasileiras, principalmente naquelas de alto prestígio acadêmico e social, acontece uma inversão, quando o ensino de graduação passa a ser considerado, na maior parte das vezes, uma atividade secundária em virtude do que vem qualificar o perfil profissional do docente universitário:

- A inserção no mundo da pesquisa;

- O número de artigos publicados em revistas indexadas e vinculadas ao Qualis/CAPES, de preferência naquelas de recomendação A (inter)nacional;

- O número de teses e dissertações que orienta;

- O número de teses e dissertações que avalia e examina;

- As conferências que profere em eventos nacionais e internacionais;

- Os trabalhos que apresenta nos eventos nacionais e internacionais;

- Os financiamentos que consegue para a realização de seus projetos de pesquisa.

O perfil traçado para o docente universitário demonstra que, na UERN, o quadro é severamente adverso às suas reais condições de trabalho. O perfil da qualidade do docente universitário é hoje traduzido pela quantidade. Nós, docentes da UERN, não estamos conseguindo imprimir um ritmo acelerado de produção acadêmica - que exprima a quantidade desejada - nem estamos conseguindo expressar efetivamente uma qualidade em decorrência das próprias condições de trabalho. Aqui, logo de cara, temos dois desafios a serem enfrentados: qualidade e quantidade. Ambos na educação superior, e não apenas nela, devem coexistir para desmistificar a farsa dos números, como o único indicador de excelência universitária. Qualidade e quantidade exigem um profundo repensar acerca do docente universitário, sua formação e seu exercício profissional.

A UERN apresenta muitos desafios acrescidos pelas exigências que a própria política educacional enseja. A situação institucional da UERN é delicada. Penso que estejamos conscien-

82 R. Faced, Salvador, n.12, p.71-87, jul/dez. 2007 
tes dos riscos que esta instituição enfrenta para atender às prerrogativas legais para manter-se com status de universidade. Os docentes da UERN, não enquanto profissionais isolados, mas enquanto corpo coletivo está hiper-fragilizado, sem condições institucionais de acompanhar e preencher os requisitos indispensáveis ao professor universitário de hoje. O rol das exigências postas para o docente universitário transforma-se, para nós, em grandes dilemas, pois:

- Não temos tradição de pesquisa, nem conseguimos imprimir um nível razoável de realização de pesquisas. Claro que em algumas áreas a situação é menos dramática do que noutras.

Ainda não temos pós-graduação stricto sensu implementada para orientar teses e dissertações. Temos propostas em fase de implementação. Orientar trabalhos de mestrado e de doutorado é uma dimensão do professor doutor que qualifica e melhora sua atuação na universidade; outra dimensão é avaliar teses e dissertações. Portanto, nossa ação profissional se mantém, de modo geral, no nível da participação em bancas para avaliar teses e dissertações ou orientar trabalhos de pós-graduação lato sensu. Ademais, a ausência da pós-graduação stricto sensu na UERN tem também engessado, sobremaneira, nossa inserção nos editais das agências financiadoras de pesquisa que, prioritariamente, direcionam seus interesses para as universidades que dispõem, em seus quadros, programas de pós-graduação stricto sensu. Dos projetos encaminhados pelos professores da UERN ao CNPq, em 2006, objetivando o fortalecimento de linhas de pesquisas nas áreas humanas e sociais, nenhum projeto conseguiu aprovação. Curioso é saber se a não aprovação é decorrência de sua qualidade ou conseqüência da ausência da pós-graduação stricto sensu em nosso meio. Sou levada a crer que a não aceitação de nossos projetos, pelo que tem predominado nas avaliações dos comitês por áreas de conhecimento do CNPq, é ausência de sua pós-graduação stricto sensu. Assim sendo, qualquer concorrência torna-se extremamente desigual já na sua largada, principalmente quando concorremos com as demais instituições que já corporificaram a pósgraduação em suas ações. 
- Temos uma política de capacitação docente stricto sensu (Mestrado e Doutorado), mas falta uma política de formação contínua no território do trabalho, de modo a acompanhar e subsidiar os professores em suas práticas cotidianas. Mestres e Doutores também precisam dar continuidade a sua formação, pois, no mundo contemporâneo movido pelo rápido desenvolvimento da ciência e da tecnologia nenhum nível de formação se coloca em caráter de terminalidade. Nessa perspectiva de compreensão, uma política contínua e consistente de formação no território do trabalho, que sirva como apoio pedagógico, consiste numa iniciativa primordial e urgente para o movimento da profissionalização docente, cabendo à Pró-Reitoria de Ensino de Graduação, em parceria com a de Pesquisa e de Extensão, prover mecanismos constantes de formação.

- Não temos ainda uma política de avaliação institucional propositiva, que seja capaz de descortinar vicissitudes e fragilidades pedagógicas como forma de possibilitar o redimensionamento de práticas e atitudes dos docentes.

- Temos um corpo docente constituído por 589 professores, dos quais 97 são graduados, 203 especialistas, 220 mestres e 69 doutores. O quadro é profundamente desafiador para uma instituição que pretende manter seu status de universidade. Observem a configuração dos dados referentes ao ano de 2006 em termos gráficos:

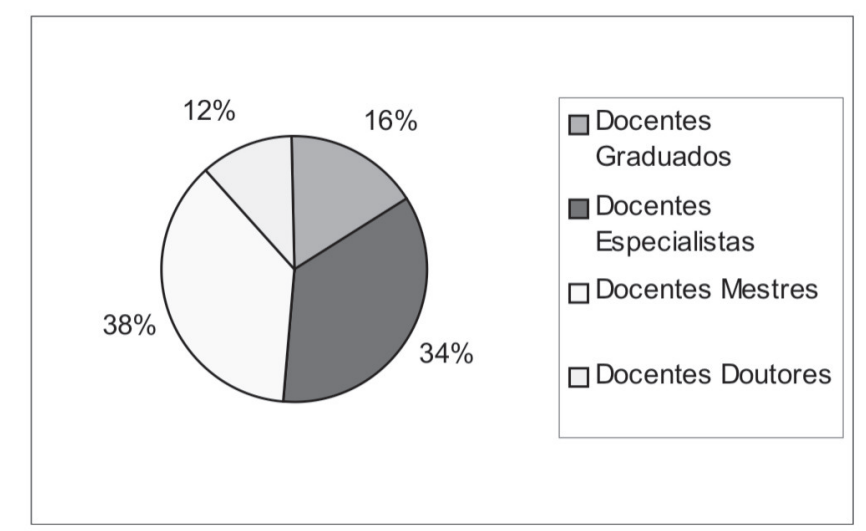

Gráfico 1: Situação da Qualificação Docente no Âmbito da UERN

Fonte: Pró-Reitoria de Recursos Humanos e Assuntos Estudantis, UERN

84 R. Faced, Salvador, n.12, p.71-87, jul/dez. 2007 
O quadro, por um lado, atende à prerrogativa legal de um terço do corpo docente com titulação de mestre ou de doutor, no entanto, torna-se profundamente desafiador para a implementação da pós-graduação stricto sensu, haja vista o baixo índice de professores doutores. Para ratificar o risco que a UERN corre diante às exigências contemporâneas relativas ao professor universitário, cabe ainda registrar:

- Não temos meios de publicação compatíveis às exigências Qualis/CAPES. Nosso único meio é a Revista Expressão, a qual não consegue exprimir certa notoriedade acadêmica;

- Temos cursos de graduação funcionando em condições precárias, conforme já mencionamos anteriormente;

- Temos docentes que precisam, em caráter de urgência, participar dos espaços formativos que os qualifiquem enquanto docentes da educação superior. Além do mais, em virtude das novas demandas educativas, particularmente no que diz respeito à inclusão de pessoas com necessidades especiais, o professor universitário não deve e nem pode acomodar-se para não se submeter ao risco de contribuir com a exclusão dos incluídos.

- Temos docentes que não se inserem nas discussões de seu campo profissional, dificultando sua própria qualificação e atualização.

Tudo isso é apenas um demonstrativo de nossos desafios, quando a questão em pauta é a profissionalização docente da educação superior em face da consolidação da instituição como Universidade. No fundo, somos avaliados não pelo que realmente somos, mas por parâmetros avaliativos postos pela política educacional que homogeneízam as diferenças. O enfrentamento dessa situação presume realçar a profissionalização docente como forma de atribuir ao ensino uma dimensão criteriosa da ação do professor, bem como desenvolver estratégias que impulsionem e estimulem os docentes ao estudo, ao aprofundamento de suas questões profissionais. No ensino superior "[...] não há lugar para o espontaneísmo e nem para a acomodação. É preciso recuperar no professor a dimensão do desejo e a firmeza de que seu trabatho vale a pena, que é preciso mudar". (CUNHA, 2006, p.6)

Diante de tal colocação, espera-se que o docente do ensino superior admita que sua prática, para atingir os fins pedagógicos a que se destina, não comporta atitudes espontâneas, nem quais- 
quer espécies de acomodação. Professores de ensino superior que se acomodaram estão perdendo a dimensão política de seu fazer social. Lamentavelmente, nos casos de acomodação do professor, quem perde é o aluno que espera da universidade um espaço aberto e possível para seu crescimento intelectual e profissional.

\section{Conclusões}

As discussões atuais que versam sobre a formação do professor do ensino superior acenam para o fato de que este profissional precisa se permitir a uma formação teórico-pedagógica, inclusive, superar o discurso comum que se instala na prática cujo desmerecimento pelos saberes relacionados à educação torna-se bastante evidente. Atuar no ensino superior exige rigor acadêmico e profissional, realidade que muitos professores desconsideram porque aprenderam que, para ensinar, o saber específico de área ou da prática é o suficiente. Todavia, a maneira mais profissional de cuidar do ensino superior é assumindo a perspectiva de que a docência não se constitui objeto de atuação para qualquer profissional que, aliás, o profissional para se tornar professor carece incorporar saberes os quais não se constituíram arcabouço teórico-metodológico de sua formação inicial, por isso há urgência em se promover estratégias de formação no próprio território de trabalho, de modo a inibir práticas desvinculadas das demandas educativas inerentes aos profundos desafios do ensino superior na atualidade.

A docência superior no âmbito da UERN tem suas particularidades, uma vez que esta instituição lida com duas necessidades simultâneas: a de avançar na possibilidade de manter seu status de Universidade e a de desenvolver mecanismos que fortaleçam o movimento da profissionalização de seus docentes, porque o que se impõe como fundamental em termos da docência no ensino superior é a premência de atribuir-se um caráter profissional à ação do professor, tendo em vista a qualidade desta ação no âmbito das universidades e, conseqüentemente, da sociedade. 
Teachers in the higher education: contemporaries challenges

ABSTRACT: This article discuss about the teachers in higher education, detaching related aspects of professional identity and challenge to the faced for a public university of Rio Grande do Norte state, when analyzed about the perspective of requirements of a educational politic for this education level. The teaching identity is, above all, a epistemological and professional construction, in which diverse knowledge articulate between itself. Then, finally, it looks to enhance that the teachers don't constitutes the object of a non-professionalized actuation, demanding, then, the use of formation strategies by the universities on they own job.

KEYWORDS: Teachers. Higher education. Professional identity.

\section{Referências}

CUNHA, Maria Isabel da. O lugar da formação do professor universitário: a condição profissional em questão. In: ENCONTRO NACIONAL DE DIDÁTICA E PRÁTICA DE ENSINO, 13., Recife, 2006. Anais... Recife: UFPE, 2006.

DOURADO, Luis Fernandes. A reforma do Estado e as políticas de formação de professores nos anos 1990. In: ; PARO, Vitor Henrique (Org.). Políticas públicas \& educação básica. São Paulo: Xamã, 2001.

GUIMARÃES, Valter Soares. A socialização profissional e profissionalização docente: um estudo baseado no professor recémingresso na profissão. In: (Org). Formar para o mercado ou para a autonomia? o papel da universidade. Campinas, SP: Papirus, 2006 .

IMBERNÓN, Francisco. Formação docente e profissional: formarse para a mudança e a incerteza. 3. ed. São Paulo: Cortez, 2002.

LEITE, Carlinda; RAMOS, Kátia. Formação para o exercício da docência universitária: caminhos delineados na Universidade do Porto. In: ENCONTRO NACIONAL DE DIDÁTICA E PRÁTICA DE ENSINO, Recife, 2006. Anais... Recife: UFPE, 2006.

MACIEL, Lizete Shizue Bomura; SHIGUNOV NETO, Alexandre. Formação de professores: passado, presente e futuro. São Paulo: Cortez, 2004.

MANCEBO, Deise; FÁVARO, Maria de Lourdes de Albuquerque (Org). Universidade: políticas, avaliação e trabalho docente. São Paulo: Cortez, 2004.

MEDEIROS, Arilene Maria Soares de. Formação de professores sob a perspectiva da teoria crítica e das políticas educacionais. Educação E Linguagem, São Bernardo do Campo, v. 8, n.11, p.195-210, jan.jun., 2005 
PARO, Vitor Henrique. Gestão democrática da escola pública. São Paulo: Cortez, 1997.

PIMENTA, Selma Garrido; ANASTASIOU, Lea das Graças Camargos. Docência no superior. 2. ed. São Paulo: Cortez, 2005.

TEODORO, António; VASCONCELOS, Maria Lúcia (Org.). Ensinar e aprender no ensino superior: por uma epistemologia da curiosidade na formação universitária. São Paulo: Mackenzie; Cortez, 2003. 